\title{
A Novel Method on the Effect of Natural Additive on Cube Crack Morphology
}

\author{
Siti Zulaikha Binti Mohamad Amin ${ }^{1}$, Syazwana Binti Mohd Sukri², Abdoullah \\ Namdar $^{3}$, Xiong Feng ${ }^{4}$, Ershad Darvishi ${ }^{5}$ and Muhammad Sajid Khan ${ }^{6}$ \\ 1,2,3,4,5 Western China Earthquake and Hazards Mitigation Research Centre, \\ College of Architecture and Environment, Sichuan University, P.R. China \\ ${ }^{6}$ College of Computer Science, Sichuan University, P.R. China \\ ${ }^{1}$ ika_gerlM@Hotmail.com
}

\begin{abstract}
Cement is the major agent in the process of construction act as a glue in material and construction industry. This paper presents the effect of copper powder when replaced 1\%, $3 \%$ and $5 \%$ of the cement amount in the concrete cube. Experimental setups were carried out to study the transitions that appears after the testing process and the concrete cube features noticed in the observation step, when copper powder react with cement, how it will transform the concrete physical characteristics? This research provide that natural additives when combined or replaced with cement bring changes in the strength and mechanical properties of the concrete from the experimental results. The morphology images of the cement paste containing 1\% of copper powder concerned while using Field Emission Scanning Electron Microscopy(FESEM) and its chemical composition was also noticed by using X-ray Diffraction(XRD) to clarified the changes occurred on the concrete with and without additive. Crack patterns on the concrete cube were explain during failure and the time of first crack also been taken during the experimental process. Apart of, compressive strength of the concrete were observe.
\end{abstract}

Keywords: copper powder, transition, compressive strength, crack patterns

\section{Introduction}

Copper is a mineral that can be collected from mines. It is actually a pure metal and a natural material. The characteristics of copper are soft, malleable and ductile metal. The mechanical features of copper are have a very high thermal conductivity and also high in electrical conductivity. While cement is a glue for concrete. Self compacting concrete is one kind from many types of concrete. Why it is called self compacting concrete? This is because, this kind of concrete does not need for mechanical vibration due to the fact that it can spread into and filled into any formwork. Self-compacting concrete can save time and labor works in the construction site.

This paper experimentally introduced the reactions occurred on the concrete when it react with copper powder. The reactions that noticed on the concrete inevitably, similar to the self compacting concrete when using super-plasticizer as an admixture to the concrete. Where super-plasticizer is an admixture that react with concrete to produced a selfcompacting concrete. Other than that, giving all the information about cement reactions with copper powder will be discussed with the help compressive strength test, FESEM and XRD results.

Natural minerals able to change the characteristics of other type of materials[1]. Cement's morphology could changed by reactions with other materials. While even temperature could effect the morphology of cement. The crystal structure in cement would changed due the increases of concrete compressive strength[1]. These information 
indicated that various parameters could be responsible in changing the cement characteristics.

The purposes of this research is to evaluate the changes the physical and mechanical properties of the concrete cube when acted with natural additive, copper powder. The copper powder will replaced $1 \%, 3 \%$ and $5 \%$ of the cement amount in mix design of concrete making. After 7 days of curing in water, the concrete cubes will tested. From the experimental result, which is compressive strength test, several transitions from the concrete cube can be stated. The results to discussed in this research are behaviors, compressive strength(stress), time of first crack, failure patterns after direct compression and cement paste morphology of the concrete cubes.

\section{Methodology}

This paper aimed on the reactions of copper powder in concrete. The methodology applied in this experimental program occurred by conducting a concrete mix design to produce concrete cubes. The experiment was done in Sichuan University's Civil Engineering laboratory that located in Jiang An campus. The program was also done in winter season. Volume of $100 \mathrm{~mm} \times 100 \mathrm{~mm} \times 100 \mathrm{~mm}$ size concrete cubes were made. The copper powder is mixed with concrete for $1 \%, 3 \%$ and $5 \%$ of cement weight and the compressive strength in the concrete for seven days of curing in water was tested. While XRD and FESEM were used in experiment to study the macro properties of the cement and material itself.

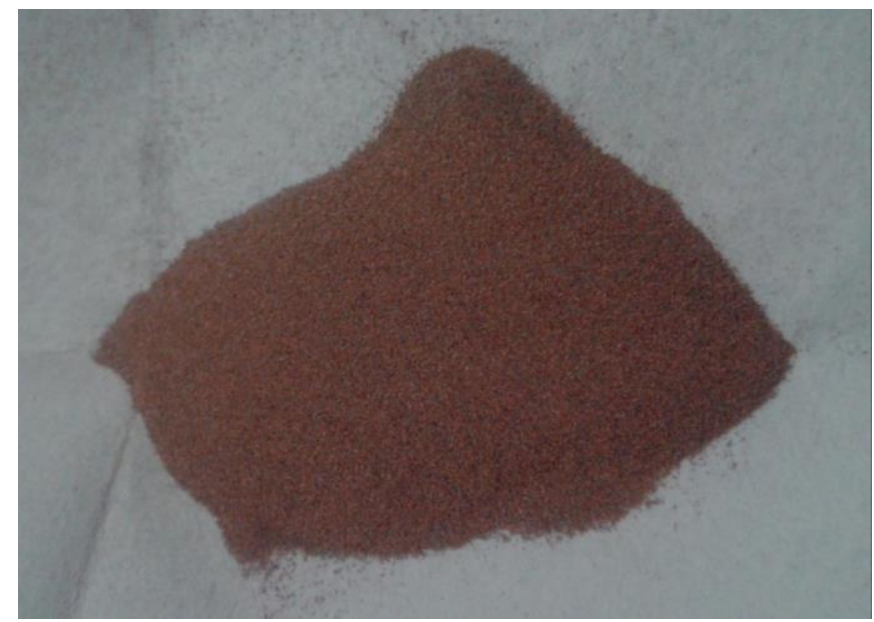

Figure 1. Copper Powder

\section{Results and Discussions}

\subsection{Concrete Behaviors}

The concrete was observed to have some changes in behavior when reacted with copper powder after 3\% replacement of cement weight. The hardened concrete identify swollen as the concrete mixture started to become solid after drying process as shown in Figure 2 and Figure 3. The concrete cube also was discovered to be increased in size as it swollen because of the reaction that happened with copper powder.

These behaviors seem to be applying that when cement reacts with copper powder, the concrete seems to have self-compacting concrete behavior. Although for the sake of this paper, vibrator was the use during the concrete mix process while in the making of selfcompacting concrete doesn't require a vibrator machine. 


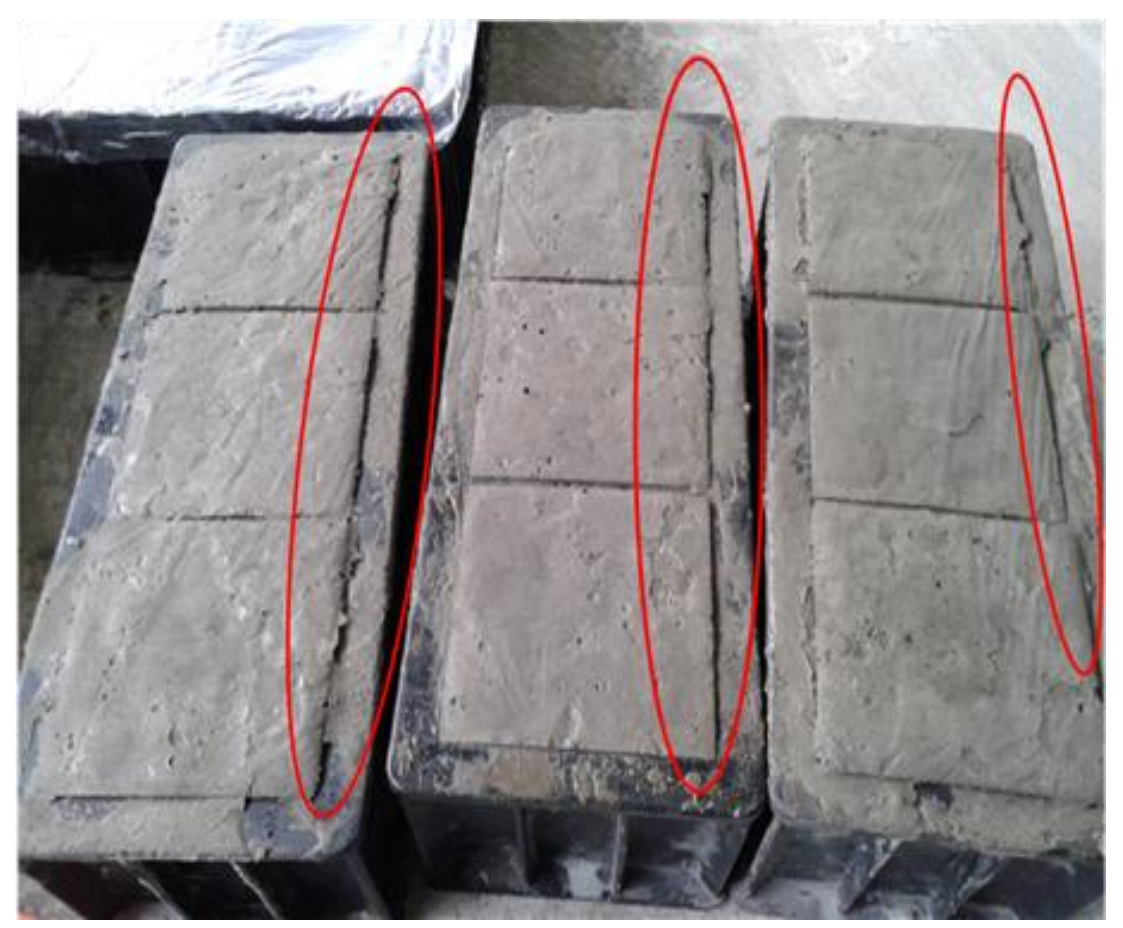

Figure 2. The Concrete Identified Swollen After Hardened

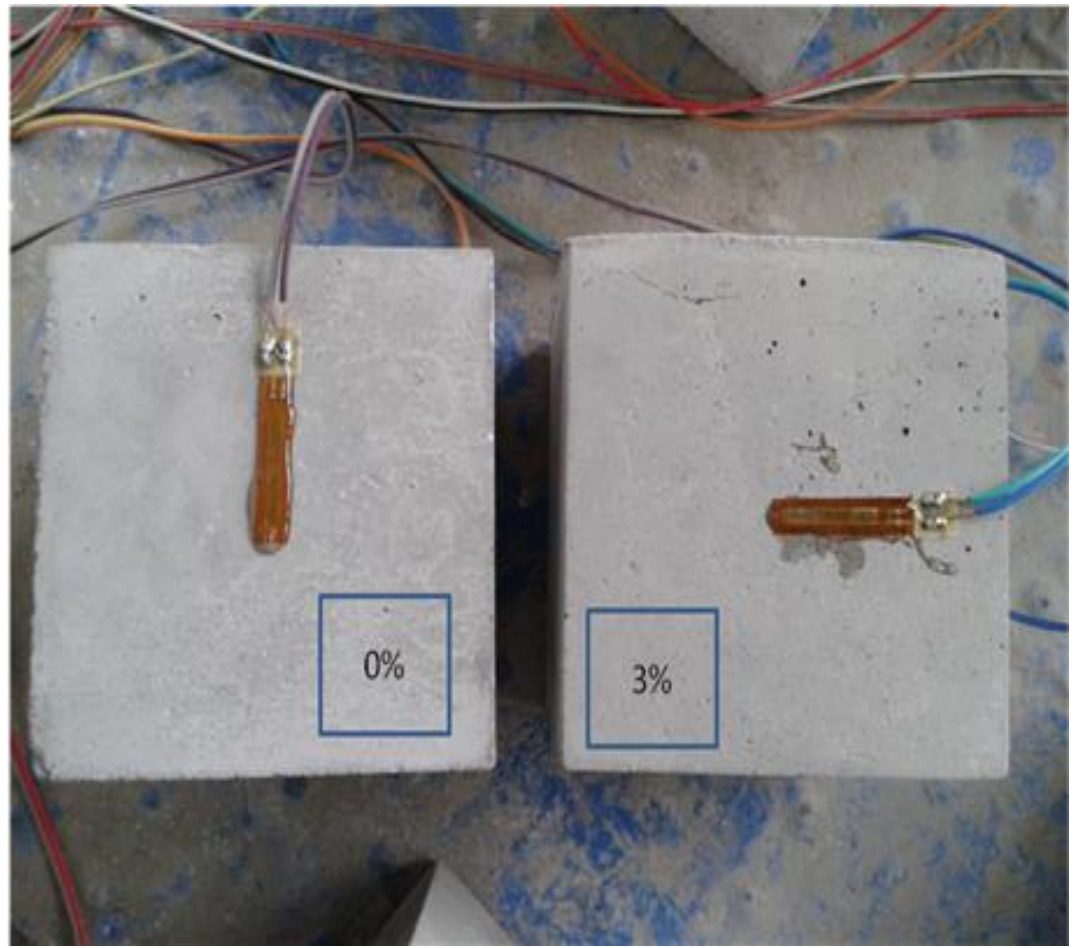

Figure 3. The Size of the Hardened Concrete Cube seen to be Changed and Increased with 3\% Additive Replacement Compared to Plain Concrete

\subsection{Compressive Strength Test}

Table 1 showing the compressive strength results from the concrete when react with copper powder. From the result, $1 \%$ of copper powder when replace in cement have the possibility to have the higher strength than plain concrete. However, the strength to the concrete decreased severely as the percentage of additive replacement increases to $3 \%$ and 
5\%. Where the physical characteristics of the concrete also changed when the percentage of the additive increases in spite of the compressive strength to the concrete could not be able to achieve higher. More than 1\% amount of copper powder in the concrete cube can decrease the compressive strength. This is quite normal as compared to other research when cement replaced with other types of additive material.

Table 1. Concrete Compressive Strength

\begin{tabular}{|c|c|c|c|}
\hline No. & $\begin{array}{c}\text { Additive } \\
\text { name }\end{array}$ & $\begin{array}{c}\text { Additive } \\
\text { percentage } \\
(\%)\end{array}$ & $\begin{array}{c}7 \text { days } \\
\text { Stress } \\
(\mathrm{MIPa})\end{array}$ \\
\hline 1 & None & 0 & 24.02 \\
\hline 2 & $\begin{array}{c}\text { Copper } \\
\text { powder }\end{array}$ & 1 & 25.17 \\
\hline 3 & $\begin{array}{l}\text { Copper } \\
\text { powder }\end{array}$ & 3 & 11.63 \\
\hline 4 & $\begin{array}{l}\text { Copper } \\
\text { powder }\end{array}$ & 5 & 8.84 \\
\hline
\end{tabular}

\subsection{Crack Patterns}

Crack pattern on the concrete is a study to define any possible changes between concrete with and without additive. The times of first cracks were taken during the application of compressive strength test and noted as soon as the crack is seen to occur during the failure process. From the result, the crack tends to occur soon as if the compression stress of the concrete considers low. However, the failure crack on concrete surface would occur later when the concrete has the highest stress as shown in Table 2. The time of the first crack of concrete with $1 \%$ of copper powder occurred in the longer time as it has the highest compressive strength among other specimens.

\section{Table 2. Time of First Crack Occurred During Compressive Strength Test}

\begin{tabular}{|c|c|c|c|}
\hline No. & $\begin{array}{c}\text { Additive } \\
\text { name }\end{array}$ & $\begin{array}{c}\text { Additive } \\
\text { percentage } \\
(\%)\end{array}$ & $\begin{array}{c}\text { Time of } \\
\text { First Crack } \\
\text { (Second, s) }\end{array}$ \\
\hline 1 & None & 0 & 154 \\
\hline 2 & $\begin{array}{l}\text { Copper } \\
\text { powder }\end{array}$ & 1 & 160 \\
\hline 3 & $\begin{array}{l}\text { Copper } \\
\text { powder }\end{array}$ & 3 & 52 \\
\hline 4 & $\begin{array}{l}\text { Copper } \\
\text { powder }\end{array}$ & 5 & 33 \\
\hline
\end{tabular}

Plain concrete is a brittle material as it fractures without any plastic deformation. The failure can occur rapidly and can be chaotic. The fracture of brittle materials when under compressive can observe clearly. The failure pattern for concrete cube shows that the failure planes intersect at approximately $45^{\circ}$ along each vertical face as shown in Figure 4(a) and 4(b). Brittle materials can suffer deterioration in hostile environments, although concrete is very durable and generally requires no maintenance. 


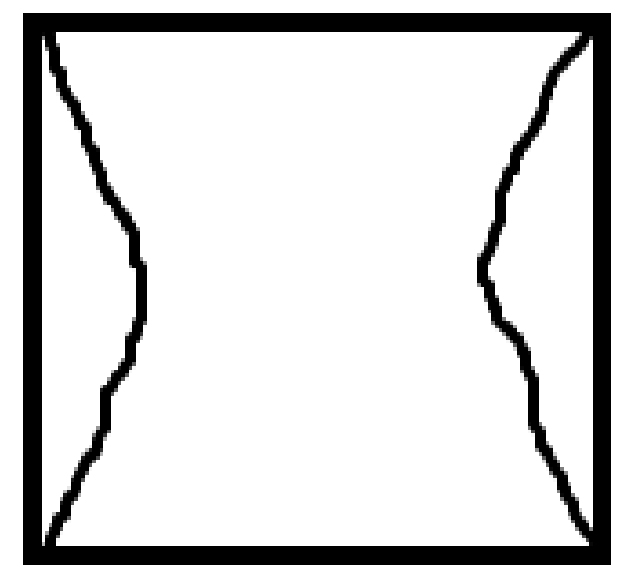

(a)

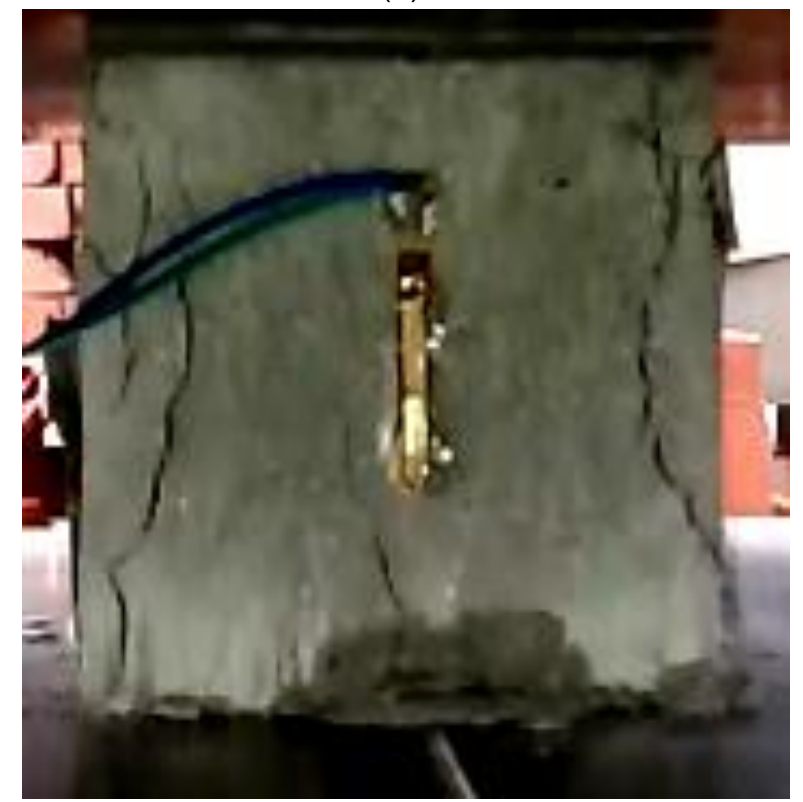

(b)

\section{Figure 4. The Cracks Morphology of the Concrete (a) Sketch of the Failure Pattern of Brittle Material (b) Failure Pattern of Plain Concrete}

Figure 5(a) and 5(b) showing the failure patterns of the concrete cube with $1 \%$ of copper powder. The failure patterns can be seen to be very chaotic than plain concrete. The crack patterns are vertically split due to shear stress. It showed a different failure patterns than the normal concrete as it is still believed to be a brittle material as it is a just concrete cube with additive. Figure 6 shows the failure mode of the concrete cube when compressive stress was applied. The failure mode in this experiment is satisfactory failure according to BS EN 12390-3: 2002 - Ideal, where the surfaces of the cube cracked almost equally along the surfaces. The cracking patterns on concrete cube's surface is cause by lateral expansion due to the compressive stress. 


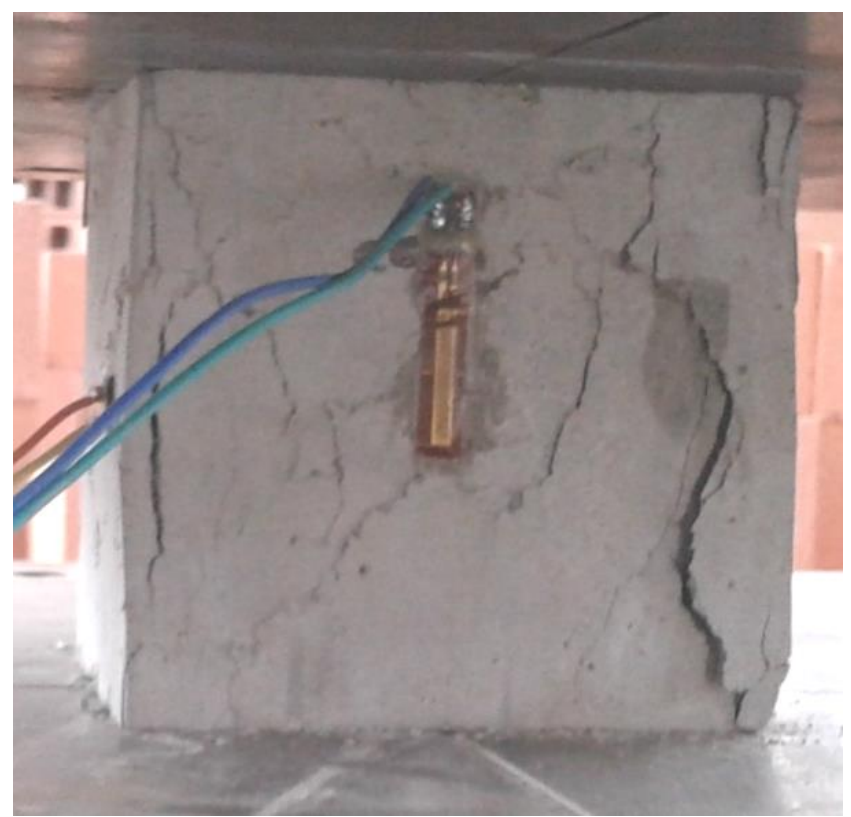

(a)

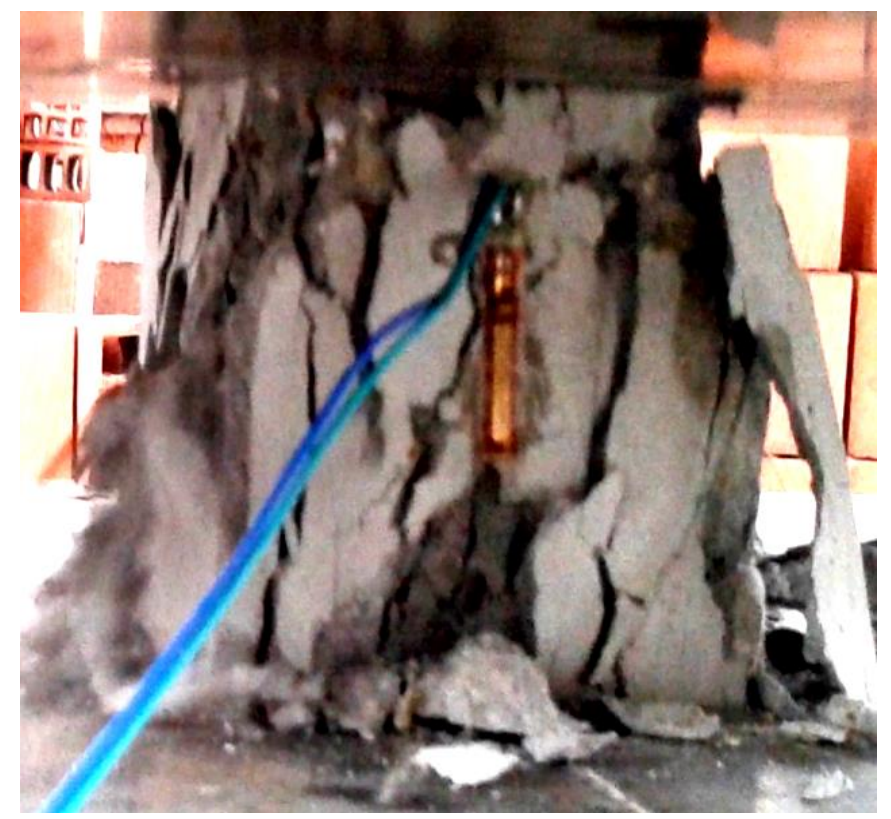

(b)

Figure 5. The Failure Patterns of Concrete with Additive (a) Failure Pattern of Concrete in the Beginning of Failure (b) Failure Pattern of the Concrete After Failure 


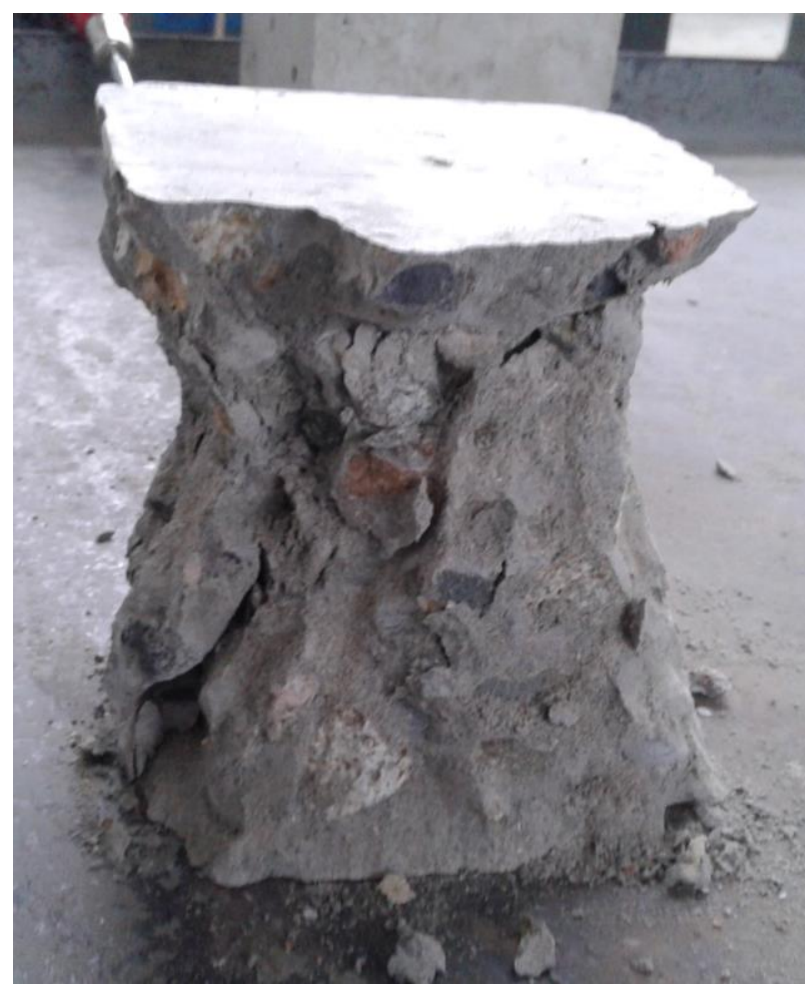

Figure 6. The Failure Mode of Concrete with Additive Under Stress

\subsection{Cement Paste Morphology}

The morphology of cement paste studied by using FESEM images and the results showing some significant differences occurred to the micro properties of the cement paste with and without additive. Figure 7 and Figure 8 shows the FESEM image of cement paste with $1 \%$ of copper powder and can be observed to have a change in the properties with plain cement paste as shown in the Figure 9. The crystal structure of the cement paste with additive is improved as shown in the Figure 10 and Figure 11 whether to be compared with the cement paste without additive. Nano fiber in the mixture has enhanced due to the natural additive.

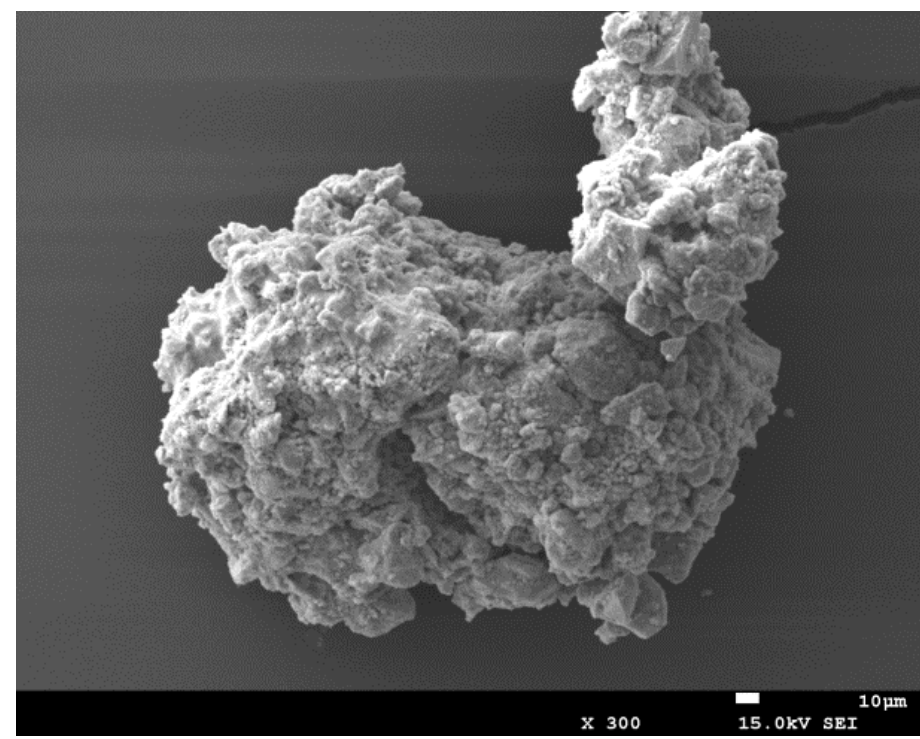

Figure 7. FESEM Image of Cement Paste with 1\% Copper Powder 


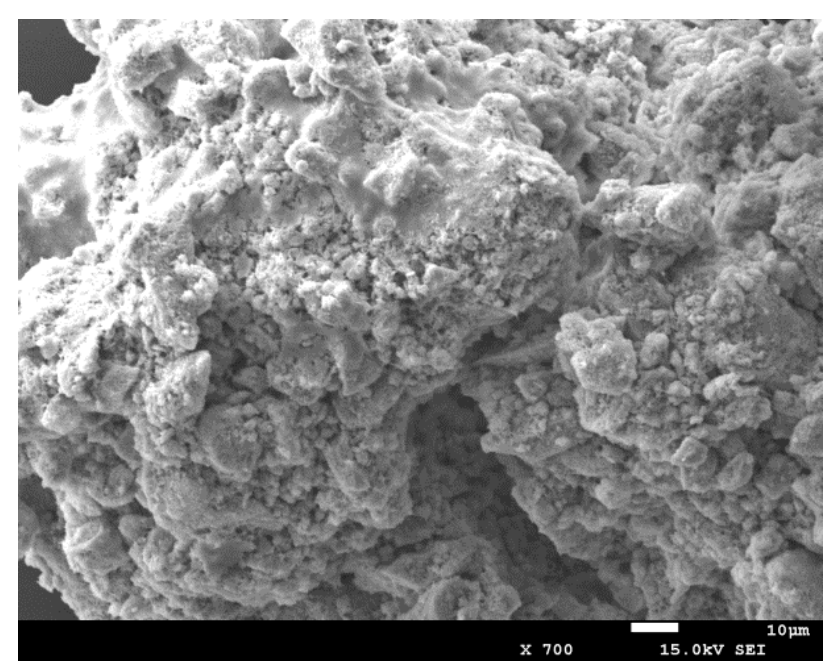

Figure 8. FESEM Image of Cement Paste with 1\% Copper Powder

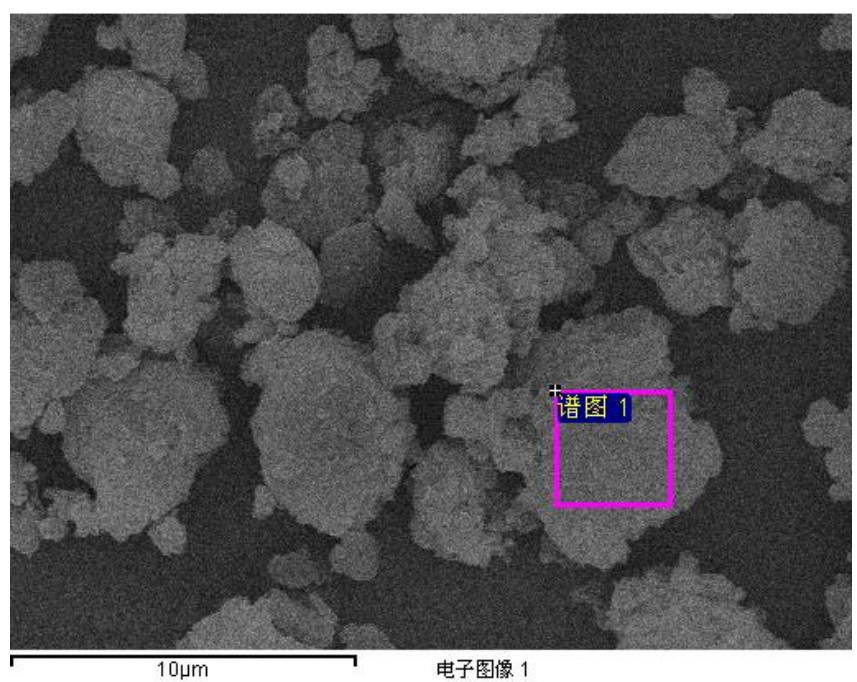

Figure 9. FESEM Image of Cement Paste Without Additive

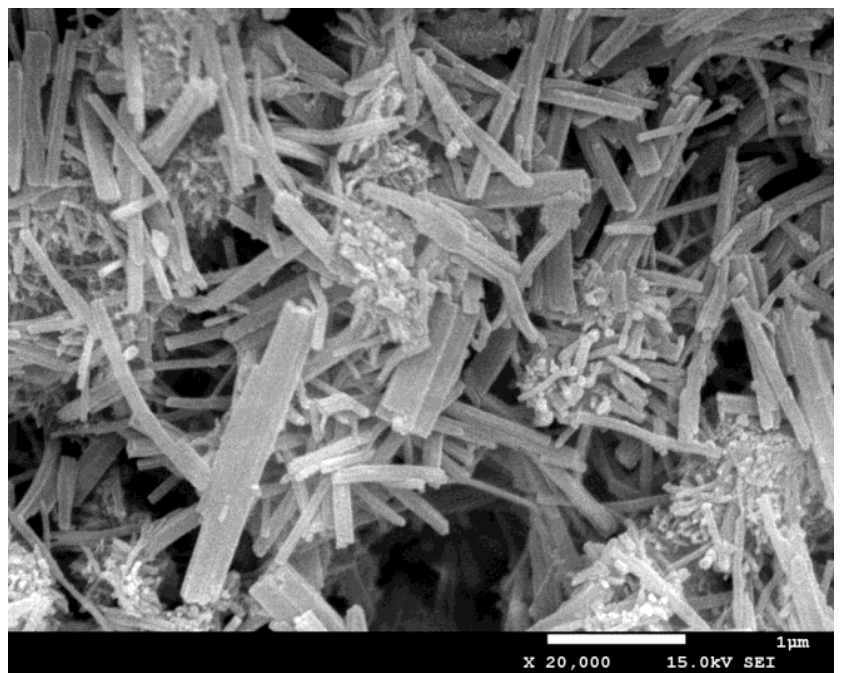

Figure 10. Image of FESEM Cement Paste with $1 \%$ of Copper Powder at $1 \mu \mathrm{m}$ 


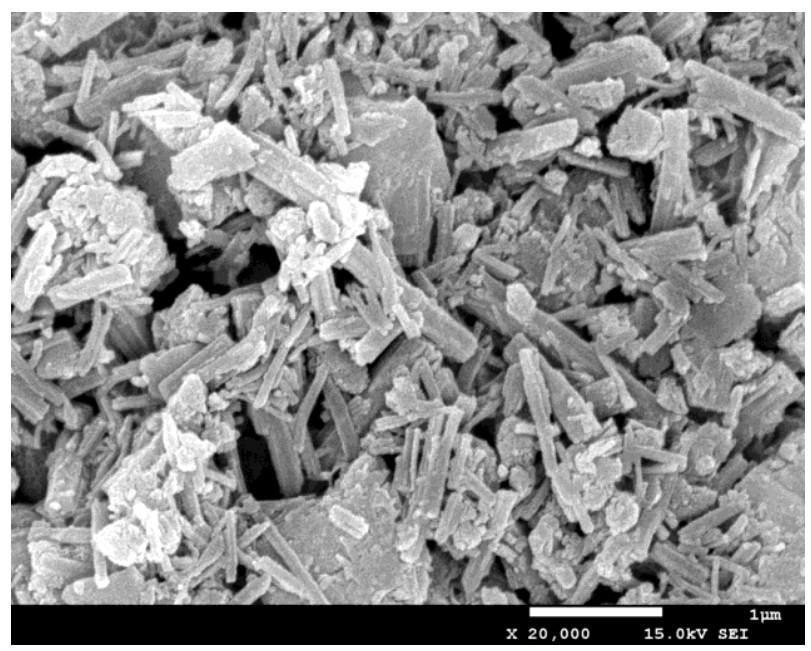

Figure 11. Image of FESEM Cement Paste with $1 \%$ of Copper Powder at $1 \mu \mathrm{m}$

\section{Recommendations}

1. Natural materials have their own chemical properties and have reactions when acted as an additive in concrete.

2. Changing the chemical properties to the materials could effect in increasing the compressive strength of the concrete.

3. Right methodology is a very important role in producing good results.

\section{Conclusions}

Copper powder when react in concrete shows some self-compacting concrete behaviors. The time of first cracks will occur sooner if the compressive strength is lower but will occur later if the compressive strength is higher. The failure patterns of the concrete cubes surface during failure showed that concrete cube with additive have insignificant crack patterns, it is very chaotic than plain concrete. The crack patterns is vertically split due to shear stress. The images of FESEM showed that nano fibers appeared when copper powder reacts with cement. The crystal structure of the cement paste with copper powder is improved where the nano fiber in the mixture has enhanced due to the natural additive.

\section{References}

[1] Abdoullah Namdar, "Natural minerals mixture for enhancing concrete compressive strength, Frattura ed Integrità Strutturale”, 22 (2012) 26-30; DOI: 10.3221/IGF-ESIS.22.04.

[2] Abdoullah Namdar, Ideris Bin Zakaria, Azimah Bt Hazeli, Sayed Javid Azimi, Abdul Syukor Bin Abd. Razak, "An experimental study on flexural strength enhancement of concrete by means of small steel fibers", Frattura ed Integrità Strutturale, 26 (2013) 22-30; DOI: 10.3221/IGF-ESIS.26.03.

[3] Abdoullah Namdar, Fadzil Mat Yahaya and Mashita Mohd Yusoff, "Using high temperature for improve compressive strength of ordinary Portland cement paste (OPC) - A new approach", Advanced Materials Research Vol. 894 (2014) pp 70-76 @ (2014) Trans Tech Publications, Switzerland.

[4] Abdoullah Namdar, Ideris Bin Zakaria, Azam Khodashenas Pelko and Nurmunira Binti Muhammad, "Natural Mineral for Improving Concrete Compressive Strength", Advanced Materials Research Vols. 875-877 (2014) pp 1490-1494

[5] A. Namdar, X. Feng, "Economical Considerations In The Development Of Construction Materials - A Review”, Engineering Review, Vol. 35, Issue 3, 291-297, 2015.

[6] Nurmunira Muhammad1, Ideris Zakaria1 And Abdoullah Namdar, "Modification Of Kaolin Mineralogy And Morphology By Heat Treatment And Possibility Of Use In Geotechnical Engineering", Int. J. Of Geomate, Dec 2013, Vol. 5, No. 2 (Sl. No. 10), Pp. 685-689 Geotec., Const. Mat. \& Env., Issn:21862982(P), 2186-2990(O), Japan. 
[7] Nurmunira Muhammad, Abdoullah Namdar, Ideris Bin Zakaria, "Improving Peat Engineering Properties by Natural Mineral Mixture", International Journal of Civil Engineering \& Geo-Environment 2 (2011).

[8] Abdoullah Namdar, Fadzil Mat Yahaya, "Oil Palm Shell Ash - Cement Mortar Mixture and Modification of Mechanical Properties", International Science Index International Journal of Civil, Structural, Construction and Architectural Engineering Vol:8 No: 2, 2014.

[9] Abdoullah Namdar, Ershad Darvishi, Xiong Feng, "Effect of flexural crack on plain concrete beam failure mechanism A numerical simulation”, Frattura ed Integrità Strutturale, 36 (2016) 168-181; DOI: 10.3221/IGF-ESIS.36.17.

[10] Sayed Javid Azimi, Sharifah Maszura Binti Syed Mohsin, Fadzil Bin Yahaya and Abdoullah Namdar, "An Investigation on Engineering Properties of Composite Beam, Research Journal of Applied Sciences”, Engineering and Technology 8(6): 702-705, 2014 ISSN: 2040-7459; e-ISSN: 2040-7467 @ Maxwell Scientific Organization, 2014.

[11] Siti Zulaikha Mohamad Amin, Xiong Feng, Abdoullah Namdar, "Conference Paper: Effect of natural additive on micro properties of concrete", Conference Paper, Jul 2015

[12] Syazwana Mohd Sukri, Xiong Feng, Abdoullah Namdar , "Conference Paper: A Comparative Composite Material In Soil Mechanics And Concrete - Review And Analytical Investigation", Conference Paper, Jul 2015.

\section{Author}

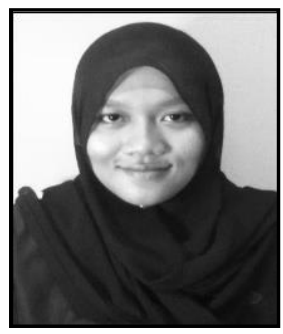

Siti Zulaikha Binti Mohamad Amin, awarded Bachelor's Degree in Civil Engineering from Universiti Malaysia Pahang, Malaysia. Currently holding Chinese Government Scholarship for continuing post graduate research in Civil Engineering in Sichuan University, China. 